\section{The contribution of sense of place to shifting cultivation sustenance: evidence from West Garo Hills, North East India}

\section{K. Pandey ${ }^{1, *}$, Amandine Junot ${ }^{2}$ and P. Adhiguru ${ }^{3}$}

${ }^{1}$ College of Horticulture and Forestry, Central Agricultural University (Manipur), Pasighat 791 102, India

${ }^{2}$ Facult_e des Sciences de l'Homme et de l'Environnement,

Universit_e de La R_eunion, Saint-Denis, France

${ }^{3}$ Agricultural Extension Division, Indian Council of Agricultural

Research, New Delhi 110 012, India

\begin{abstract}
Nowadays, sense of place is increasingly becoming prevalent in environmental research. It is an interesting concept to study both attachment and emotional relationships that individuals or groups hold for a specific place. In order to understand such bonds to forested landscape and shifting cultivation (SC) among tribal communities, we employed a four-dimensional place attachment model and empirically tested it using factor analysis. The results of this study revealed that besides socio-economic factors which affect the bonds to a place and the place-based practice, strong connections with the natural environment and lack of alternative occupations are significant factors which might explain tribal dependence to the land and SC. Indeed, sense of place would allow a better understanding of territorial issues and favour place management.
\end{abstract}

Keywords: Forested landscape, indigenous people, sense of place, shifting cultivation.

IN Asia, shifting cultivation (SC) is at the core of cultural farming practice. As the heritage of indigenous people, SC depicts culture and life in most countries in Asia ${ }^{1}$. Indeed, through various connections between people and lands or forests, SC contributes to livelihood and wellbeing of the people ${ }^{2}$. However, this practice raises various questions about land issues ${ }^{3}$, and in some countries, particularly in Southeast Asia, there is an attempt by the Governments to replace it $^{4-6}$.

Therefore, conflicts persist between the Governments and indigenous people, who despite the ban, continue to illegally practice SC. In the Eastern Himalayan region, $\mathrm{SC}$ contributes to livelihood security and ecosystem services $^{7,8}$. In North East India, SC is predominant indigenous practice and depicts the daily life of the tribal people. The Sixth Schedule of the Indian Constitution provided the tribal people of NE India a role in their land development. Moreover, the Indian Parliament has enacted the Scheduled Tribes and Other Traditional Forest Dwellers (Recognition of Forest Rights) Act 2006, which has two

\footnotetext{
*For correspondence. (e-mail: dkpextension@gmail.com)
}

purposes. Firstly, to undo the historical injustices suffered by tribal communities and recognize the rights of forest-dwelling communities. Secondly, by encouraging indigenous people to manage their lands, this Act helps harmonize the management of forests and wildlife 9 . In other words, the idea is to limit external influence or pressures, and respect the local traditions and needs ${ }^{10}$. The management of forests is transferred to the tribal councils, whose responsibilities are above those of the district Council regarding conservation of forests and wildlife within their areas in NE India ${ }^{11}$. In such situations, focus on sense of place may help better understand $\mathrm{SC}$, forest and wildlife management. Moreover, this would highlight the opportunities and challenges to collaborations between the different actors and ultimately the means of planning.

Sense of place is an important concept for understanding how people establish relations with their surroundings. Sense of place can be defined as the bonds and the emotional relationships attached to a spatial setting by a person or a group ${ }^{12,13}$. It encompasses physical elements, but also reflects social and cultural experiences and interactions with the place ${ }^{14,15}$. Indeed, sense of place is conceived as a multidimensional construct organized within a general framework of attitude structures that incorporate cognitive, affective and conative responses to spatial settings ${ }^{12}$. These responses can take form through various place concepts encompassed in sense of place, like place attachment, identity or dependence and place meanings, etc. Place attachment is an emotional bond between individuals or groups and their environment ${ }^{16}$. It is often conceived as a bi-dimensional concept, with place identity and place dependence. Place dependence is considered as a feeling due to a positive evaluation of a place on the basis that it meets an individual's needs and enables them to fulfil their goals ${ }^{17,18}$. It measures how a place can satisfy the needs of a person, or accomplish a specific goal ${ }^{19,20}$. Place identity is defined as 'those dimensions of self that define the individual's personal identity in relation to the physical environment ${ }^{21}$. Place elements thus become partial answers to the symbolic question of 'Who am I?'. Place meaning refers to symbolic or interpretive elements of the place. It refers to what a place means for people $\mathrm{e}^{22}$. In the present study, these aspects have been observed through economic bonding, the lack of alternative occupations, traditional and nature bonding.

As suggested by the United Nation (2014), to address sustainable development issues, we need to understand the integrated socio-ecological systems. Hence, we have to understand the values, cognitions and perceptions around the nature-human relationships and the interconnections with the ecosystem ${ }^{2-25}$. Sense of place theory and methods reveal interconnections between social and biophysical reality. It is 'considered as a motivation for stewardship and actions to care for the environment ${ }^{22}$. In fact, sense of place assessments can predict intention to 
accept or reject land-use planning decisions ${ }^{26}$, and it can be used as baseline information for landscape management. As suggested in a study, place-based relationships can help identify specific landscape and cultural features and ultimately, it could bring appropriate model of planning $^{13}$. For example, researchers showed that in planning for a national forest landscape in Colorado, USA, placebased meaning allowed better understanding and integrating traditional values in the decision-making processes ${ }^{27}$. In the case of forest management, sense of place would help clarify the impacts of forest management policies on different communities ${ }^{28}$. This would enhance our ability to formulate appropriate plans for the welfare of the local communities, and thus reduce polarization and related social and economic costs. Therefore, based on sense of place concept, this study sought to understand SC practice in NE India, its social reality and how to manage this practice for sustainable development and to avoid landuse conflict.

The present study was conducted during 2016-2017 in West Garo Hills district $\left(25^{\circ} 34^{\prime} 4.57^{\prime \prime} \mathrm{N}, 90^{\circ} 13^{\prime} 28.08^{\prime \prime} \mathrm{E}\right)$, Meghalaya, NE India. The district is mostly covered by forest $(77.16 \%)^{29}$ and is sparsely populated (175 people per $\left.\mathrm{km}^{2}\right)^{30}$. The Garos are the main tribe, and the other indigenous inhabitants are the Hajongs, Rabhas, Koches, Rajbansis, Meches, Kacharis and Dalus. In the Garo hills, a major proportion of the forest belongs to private ownership; the Government has only a few forest lands $(>10 \%)$. The Garo Hills Autonomous District Council manages majority of the forest area and is in charge of its use and upkeep. This study was conducted among 90 households (tribal respondents) who are randomly selected from five village clusters from two Tribal Development Blocks, namely Rongram and Gambegre. Tippet's random number series was consulted for random selection. In order to collect qualitative and quantitative data, we used structured interview schedule. Sense of place was apprehended with a four-dimensional model of place attachment based on the study by Raymond et al. ${ }^{31}$. This model includes nature bonding (connections to the natural environment), economic bonding (subsistence link), social bonding (community attachment, attachment to traditional institutions) and lack of alternative occupations. These were rated on a five-point Likert scale, ranging from 1 ('strongly disagree') to 5 ('strongly agree'). For negatively worded statements, scoring was reversed. Factor analysis was used to determine the validity of the attachment scale. The survey instrument consisted of 23 place attachment statements taken from previous studies which demonstrated high internal consistency. Nature bonding scale was developed from affiliation nature concept $^{32}$ and nature connectedness concept ${ }^{33}$. Social bonding items were developed based on the measures proposed by Kyle et al. ${ }^{34}$. Inter-item correlations and item-to-total correlations of each item were performed, followed by an exploratory factor analysis (principal component analysis with varimax rotation) as enunciated by Pearson. The criterion used by Hammitt et al. $^{35}$ was followed in forming factors, i.e. eigenvalue $\geq 1.0$, factor loading $\geq 0.40$.

First, we observed demographical variables and their repartition in the sample, since place attachment varies according to demographic characteristics like age, education, family size, farm husbandry skills/experience and household's income ${ }^{16,36,37}$. Data show that middle-aged $(45.6 \%)$ and the advanced age groups (40\%) were more represented in the sample. Maximum respondents $(62.22 \%)$ had up to primary school level of education; only $24.44 \%$ were educated above high school (Table 1 ). There were approximately six persons per family who practiced SC. Among SC practitioners, 77.8\% of them had medium size families having around 4 to 8 persons per family. Of the sample studied, $64 \%$ of the respondents had more than $25 \%$ level of dependence on SC. With regard to well-being, majority were concerned about their future. In the sample, $29 \%$ of the people considered that their well-being is in danger and $51 \%$ mentioned that they will have to struggle in the future. Table 1 summarizes these analyses.

Principal component and reliability analyses indicated four underlying dimensions with high reliabilities (Table 2, Cronbach alphas: $>0.70$ or higher).

The eigenvalue showed the importance of each of principal component. On the basis of Cattell's scree plot (Figure 1), three factors were retained. Together these factors explained over $99.83 \%$ of the total variability in the data. This led us to the conclusion that a factor solution will probably be adequate. Factor loadings indicated the strength of the correlations between each of the three factors and the variables with a high reliability (Cronbach alpha $>0.90$ ). The study has validated three dimensions: economic bonding, traditional bonding and nature bonding. Four items were found to be related to economic bonding. The item, 'Non-timber based forest products (NTFP) fetches more income from the SC land' loaded less strongly on economic bonding dimension than that of other measures of economic bonding. However, this scale was still significant and contributed strongly (factor loading $>0.88$ ). Traditional institutional bonding emerged as a more efficient dimension with maximum of six loaded items. And, four items were loaded on nature bonding. Moreover, in this study, nature bonding emerged as the first significant factor of place attachment and for the maintenance of SC. Lack of alternative occupations appeared as the second most important factor, followed by economic bonding and traditional institutions' bonding.

The study revealed that in the West Garo Hills district people seem to be highly dependent on forested landscape for their survival. The sense of place concept allowed us to understand this dependency and to explain the maintenance of SC. In fact, this study emphasizes the importance of economic factors and the lack of alternative 
RESEARCH COMMUNICATIONS

Table 1. Summary of respondents' profile

\begin{tabular}{|c|c|c|c|c|c|}
\hline \multirow[b]{2}{*}{ Variables } & \multicolumn{5}{|c|}{ Respondents } \\
\hline & Frequency & Percentage & Mean & Standard deviation & Coefficient of variation $(\%)$ \\
\hline Age (yrs) & & & 44.84 & 10.84 & 24 \\
\hline Young (18-35) & 13 & 14.44 & & & \\
\hline Middle $(36-50)$ & 41 & 45.56 & & & \\
\hline Old (Above 50) & 36 & 40.00 & & & \\
\hline Illiterate & 12 & 13.33 & & & \\
\hline Primary & 56 & 62.22 & & & \\
\hline High school and above & 22 & 24.44 & & & \\
\hline Family size & & & 5.56 & 1.83 & 33 \\
\hline Small $(<4)$ & 10 & 11.11 & & & \\
\hline Medium (4-8) & 70 & 77.78 & & & \\
\hline Large $(>8)$ & 10 & 11.11 & & & \\
\hline Corrugated steel roofed & 67 & 74.45 & & & \\
\hline Cement concrete roofed & 13 & 14.44 & & & \\
\hline \multicolumn{6}{|c|}{ Extent of dependence on shifting cultivation (SC; \%) } \\
\hline $5-25$ & 32 & 35.56 & & & \\
\hline $25-50$ & 43 & 47.78 & & & \\
\hline $50-75$ & 15 & 16.66 & & & \\
\hline $75-100$ & 0 & 0 & & & \\
\hline \multicolumn{6}{|l|}{ Well-being index } \\
\hline Suffering ( 4 and below) & 26 & 28.89 & & & \\
\hline Struggling ( 5 to 6$)$ & 46 & 51.11 & & & \\
\hline Thriving $(7+)$ & 18 & 20.00 & & & \\
\hline Household income (INR) & & & 8240.56 & 8477.17 & \\
\hline \multicolumn{6}{|l|}{ Poverty } \\
\hline Below international poverty line & 35 & 48.29 & & & \\
\hline Above international poverty line & 55 & 51.71 & & & \\
\hline
\end{tabular}



Figure 1. Fraction of total variance in the data as explained by each principal component.

solutions as factor of place attachment among the tribals. It suggests that timber resources and food are predominant variables. In the West Garo Hills district, respondents by and large are dependent on SC which implies that SC guarantees economic security, where about $48 \%$ of the respondents are experiencing extreme poverty
(Table 1). Forests and culture system are essential for livelihood and subsistence income ${ }^{38}$. Economic factors and place dependence seem to influence each other. In fact, poverty leads to strong dependency to forest activities which sustain $\mathrm{SC}^{39}$ and places that provide income for residents influence place attachment ${ }^{40}$. Nowadays, SC seems to be the only source of livelihood for the tribal population. Thus, in this study, tribals expressed the lack of other opportunities to ensure food security of their households (Table 2). There was absence of any off-farm employment $^{10,41}$ and also other employment opportunities in the villages. Therefore, out of necessity, tribal populations continue their traditional practices. For example, the Supreme Court of India has banned timber extraction and coal mining in forest areas. Hence, cultivators returned to $\mathrm{SC}$ practices and also resorted to illegal practices like charcoal making (Meghalaya), and poppy and cannabis cultivation (Manipur) for income ${ }^{42}$. Tribals prefer to live near forest areas due to their higher dependency on natural resources. Moreover, they are aware of only poor and backward technologies ${ }^{43}$, and therefore they have no other recourse than opt for SC.

In times of environmental or social changes, economic realities influence the extent of attachment to the place 
Table 2. Principal component analysis of place attachment among tribals

\begin{tabular}{|c|c|c|c|c|c|}
\hline Statement & $\begin{array}{l}\text { Factor } \\
\text { loading }\end{array}$ & $\begin{array}{l}\text { Grand } \\
\text { mean }\end{array}$ & $\begin{array}{l}\text { Item } \\
\text { mean }\end{array}$ & $\begin{array}{l}\text { Standard } \\
\text { deviation }\end{array}$ & $\begin{array}{l}\text { Cronbach } \\
\text { alpha }\end{array}$ \\
\hline \multicolumn{6}{|l|}{ Economic bonding } \\
\hline (eigenvalue $=3.64 ;$ variance explained $=91.10 \%)$ & & 3.91 & & & 0.92 \\
\hline Tribals have better access to timber resources & 0.99 & & 4.39 & 0.60 & \\
\hline $\begin{array}{l}\text { Nowadays, in SC commercial-oriented crops are preferred to } \\
\text { subsistence-based food crops }\end{array}$ & 0.91 & & 3.34 & 0.97 & \\
\hline $\begin{array}{l}\text { Non-timber based forest products (NTFP) fetch more income from } \\
\text { the SC land }\end{array}$ & 0.95 & & 3.94 & 0.57 & \\
\hline $\mathrm{SC}$ is a major source of food security for tribals & 0.97 & & 3.98 & 0.70 & \\
\hline \multicolumn{6}{|l|}{ Traditional institution bonding } \\
\hline (eigenvalue $=0.33 ;$ variance explained $=8.18 \%$ ) & & 4.02 & & & 0.92 \\
\hline $\begin{array}{l}\text { The collective process of decision-making is not observed in } \\
\text { managing the SC land resources }\end{array}$ & 0.94 & & 3.77 & 0.95 & \\
\hline $\begin{array}{l}\text { Even now for jhum, the exchange of labour among family members } \\
\text { is governed by ancient norms }\end{array}$ & 0.67 & & 3.65 & 1.14 & \\
\hline The customary laws are not as strong as in the past years & 0.96 & & 4.56 & 0.57 & \\
\hline $\mathrm{SC}$ has to be continued generation after generation & 0.86 & & 4.05 & 0.89 & \\
\hline $\begin{array}{l}\text { The present generation does not manage SC resources well like their } \\
\text { forefathers. }\end{array}$ & 0.99 & & 4.19 & 0.66 & \\
\hline The common property land tenure regime is best for SC maintenance & 0.94 & & 3.88 & 0.59 & \\
\hline \multicolumn{6}{|l|}{ Nature bonding } \\
\hline (eigenvalue $=0.03 ;$ variance explained $=0.63 \%$ ) & & 4.04 & & & 0.99 \\
\hline SC activity is laborious than settled cultivation & 0.98 & & 4.24 & 0.55 & \\
\hline Tribals have abundant SC land & 0.99 & & 3.95 & 0.72 & \\
\hline $\mathrm{SC}$ is more affected by climate change & 0.98 & & 4.26 & 0.56 & \\
\hline $\begin{array}{l}\text { The failure of one crop in SC is not a problem as tribals grow a variety } \\
\text { of food crops }\end{array}$ & 1.00 & & 3.72 & 0.84 & \\
\hline \multicolumn{6}{|l|}{ Lack of alternate occupation } \\
\hline (eigenvalue $=0.004 ;$ variance explained $=0.09 \%$ ) & & 3.69 & & & 0.96 \\
\hline There is no livelihood opportunity apart from SC & 0.98 & & 3.60 & 0.86 & \\
\hline Tribals do not have knowledge to pursue non-SC activities & 0.90 & & 3.32 & 0.98 & \\
\hline $\begin{array}{l}\text { Off-farm opportunities of high income may prompt tribals to } \\
\text { move away from SC }\end{array}$ & 1.00 & & 3.88 & 0.96 & \\
\hline $\begin{array}{l}\text { Absence of good employment opportunities in the village forces } \\
\text { the younger generation to continue ancestral occupation of SC }\end{array}$ & 0.99 & & 3.94 & 0.84 & \\
\hline
\end{tabular}

and SC. This study suggests that stakeholders can benefit by examining the emotional and functional support that place provide for people and their implications for economic life. Authorities may consider collecting information on factors which improve place capacity to support the needs of indigenous people and also may have to understand the prevailing dynamic cause and effect linkages between the people and SC. Beyond economic criteria and livelihood, nature bonding and traditional institution's bonding are significant factors of place attachment among tribals. Beyond survival goals, nature is part of the daily life of tribals. There is a strong connection between tribal populations and nature (Table 2). This nature-man connection is rooted in their lifestyle and culture, and they consider plants and trees and surrounding areas as sacred and protect them with their indigenous knowledge $\mathrm{e}^{44}$. For example, people of Garo Hills used their varied traditional ecological knowledge and thus have a reasoned management of lands by practicing long fallow system. Such SC is generally sustainable and is the best cropping method in areas where flat land is not availa- ble ${ }^{45}$. Moreover, according to tribal farmers, despite climate change and its effects, their systems generate sufficient resources since they are varied. Moreover, SC is rooted in their culture and traditions, and this practice is the way of preserving their rich cultural tradition and diversity ${ }^{5}$. There are also many festivals celebrated in connection with SC in the Garo Hills, which keep people closer to their traditional practices and allow them to develop social bonding ${ }^{46}$. Therefore, for tribal populations, $\mathrm{SC}$ shall continue, since it is intertwined with their identity and place identity. A study has pointed to the importance of understanding shared place specific emotional and functional relationships in building consensus and collective actions for transformation aided by supportive interventions ${ }^{47}$. Therefore, we have to follow humanvalued prioritization approach while making land-use planning and adopting consistent environmental and conservation planning ${ }^{19}$.

This is a preliminary study to bridge the gap between the sense of place literature and sustainability transition issues applied to SC. The aim of this study was to go 


\section{RESEARCH COMMUNICATIONS}

beyond the trivial argument that 'the place matters for sustainability transitions'. Physical attributes of a place are not enough; we need a place-based perspective. Placebased approaches would allow clarifying local contexts, values and priorities ${ }^{48}$, and the role of place-people relationship and ultimately, how relation to place can contribute to sustainability transitions policies. With evidence from this case study, we contend that the place becomes an attractor and a medium for sustainability of SC and other forest uses. We have shown that experimenting is one important way to address sustainability transitions, and not only a means to instigate or catalyse them per se. We can emphatically say that, not considering 'peopleplace relationship' does not guarantee a successful implementation of sustainable policies. In order to practice 'just planning' - an approach which considers the cultural dynamics of a place while planning any intervention - it is necessary to understand how people invest in a place, and how the place contributes to their daily life. Through sense of place study, we can explore alternative narratives, meanings and relations, and it would be possible to propose ideal, adapted transitions which are consistent with prevailing people-place relationship.

1. AIPP and IWGIA, Who we are: indigenous peoples in Asia. Briefing Paper, Chiang Mai, AIPP Printing Press, 2010.

2. Fox, J., Castella, J. C. and Ziegler, A. D., Swidden, rubber and carbon: Can REDD+ work for people and the environment in Montane Mainland Southeast Asia? Global Environ. Change, 2014, 29, 318-326.

3. Cherrier, J., Maharjan, S. K. and Maharjan, K. L., Shifting cultivation: misconception of the Asian Governments. J. Int. Dev. Coop., 2018, 24(1), 71-82.

4. Comte, I., Davidson, R., Lucotte, M., de Carvalho, C. J. R., de Assis Oliveira, F., da Silva, B. P. and Rousseau, G. X., Physicochemical properties of soils in the Brazilian Amazon following fire-free land preparation and slash-and-burn practices. Agric. Ecosyst. Environ., 2012, 156, 108-115.

5. Erni, C., Shifting cultivation, livelihood and food security: New and old challenges for indigenous peoples in Asia. Food and Agriculture Organization, International Work Group for Indigenous Affairs, Asia Indigenous Peoples Pact, Bangkok, 2015.

6. Mertz, O. and Bruun, T.B., Shifting cultivation policies in Southeast Asia-does criminalizing traditional farming practices make them go away. In Shifting Cultivation Policy: Trying to Get it Right (ed. Cairns, M.), Earthscan Routledge Press, Oxon, 2016.

7. Kerkhoff, E. and Sharma, E., Debating shifting cultivation in the Eastern Himalayas: Farmers' innovations as lessons for policy, International Centre for Integrated Mountain Development, Nepal, 2006.

8. Dressler, W. H. et al., The impact of swidden decline on livelihoods and ecosystem services in Southeast Asia: a review of the evidence from 1990 to 2015. Ambio, 2017, 46(3), 291-310.

9. Bhullar, L., The Indian Forest Rights Act 2006: a critical appraisal Law Environ. Dev. J., 2008, 4, 20.

10. Rao, M. G., Mukherjee, C., Bhasin, A., Barua, A., Anand, M., Pandey, R. and Srinivasan, R., Vision document for the State of Meghalaya 2030. National Institute of Public Finance and Policy, New Delhi, Noida, 2011.

11. Menon, V., Kaul, R., Tiwari, S. K., Kyarong, S. and Dutta, R., Canopies and corridors-conserving the forest of Garo Hills with elephant and gibbon as flagships. Conservation Series, Wildlife Trust of India, Noida, 2010.

12. Jorgensen, B. S. and Stedman, R. C., Sense of place as an attitude lakeshore owners attitudes toward their properties. J. Environ. Psychol., 2001, 21(3), 233-248.

13. Lin, C. C. and Lockwood, M., Assessing sense of place in natural settings: a mixed-method approach. J. Environ. Plann. Manage., 2014, 57(10), 1441-1464.

14. Alawadi, K., Place attachment as a motivation for community preservation: the demise of an old, bustling, Dubai community. Urban Stud., 2017, 54(13), 2973-2997.

15. Eisenhauer, B. W., Krannich, R. S. and Blahna, D. J., Attachments to special places on public lands: an analysis of activities, reason for attachments, and community connections. Soc. Nat. Resour., 2000, 13(5), 421-441.

16. Altman, I. and Low, S., Place Attachment, Plenum Press, New York, USA, 1992.

17. Backlund, E. A. and Williams, D. R., A quantitative synthesis of place attachment research: investigating past experience and place attachment. In (Murdy, J.), Proceedings of the 2003 Northeastern Recreation Research Symposium; 2003 April 6-8; Bolton Landing, NY. Gen. Tech. Rep. NE-317. Newtown Square, PA: US Department of Agriculture, Forest Service, Northeastern Research Station, 2004, pp. 320-325.

18. Stokols, D. and Shumaker, S., People in place: a transactional view of settings. In Cognition, Social Behavior and the Environment (ed. Harvey, J.), Lawrence Erlbaum, Hillside, NJ, 1981.

19. Brown, G. and Raymond, C., The relationship between place attachment and landscape values: toward mapping place attachment. Appl. Geogr., 2007, 27(2), 89-111.

20. Junot, A., Paquet, Y. and Fenouillet, F., Place attachment influence on human well-being and general pro-environmental behaviors. J. Theor. Soc. Psychol., 2018, 2(2), 49-57.

21. Proshansky, H. M., The city and self-identity. Environ. Behav., 1978, 10(2), 147-169.

22. Masterson, V. A., Stedman, R. C., Enqvist, J., Tengö, M., Giusti, M., Wahl, D. and Svedin, U., The contribution of sense of place to social-ecological systems research: a review and research agenda. Ecol. Soc., 2017, 22(1), 49.

23. Chan, K. M. et al., Why protect nature? Rethinking values and the environment. Proc. Natl. Acad. Sci. USA, 2016, 113(6), 14621465.

24. Raymond, C. M. et al., Ecosystem services and beyond: Using multiple metaphors to understand human-environment relationships. BioScience, 2013, 63(7), 536-546.

25. von Heland, J. and Folke, C., A social contract with the ancestors - culture and ecosystem services in southern Madagascar. Global Environ. Change, 2014, 24, 251-264.

26. Tapsuwan, S., Leviston, Z. and Tucker, D., Community values and attitudes towards land use on the Gnangara Groundwater System: a sense of place study in Perth, Western Australia. Landsc. Urban Plann., 2011, 100(1-2), 24-34.

27. Cheng, A. S. and Mattor, K. M., Place-based planning as a platform for social learning: insights from a national forest landscape assessment process in Western Colorado. Soc. Nat. Resour., 2010, 23(5), 385-400.

28. Kruger, L. E., Understanding community-forest relations. US Department of Agriculture, Forest Service, Pacific Northwest Research Station, USA, 2003.

29. FSI, India State of Forest Report, 2017. Forest Survey of India, Dehradun, 2017.

30. Chandramouli, C. and General, R., Census of India. Rural-urban distribution of population, provisional population total. Office of the Registrar General and Census Commissioner, New Delhi, 2011.

31. Raymond, C. M., Brown, G. and Weber, D., The measurement of place attachment: personal, community, and environmental connections. J. Environ. Psychol., 2010, 30(4), 422-434. 
32. Kals, E., Schumacher, D. and Montada, L., Emotional affinity toward nature as a motivational basis to protect nature. Environ. Behav., 1999, 31(2), 178-202.

33. Schultz, P. W., The structure of environmental concern: concern for self, other people, and the biosphere. J. Environ. Psychol., 2001, 21(4), 327-339.

34. Kyle, G., Graefe, A. and Manning, R., Testing the dimensionality of place attachment in recreational settings. Environ. Behav., 2005, 37(2), 153-177.

35. Hammitt, W. E., Backlund, E. A. and Bixler, R. D., Place bonding for recreation places: conceptual and empirical development. Leisure Stud., 2006, 25(1), 17-41.

36. Dey, P. and Chattopadhyay, S., Impact of socio-economic status on place and dwelling attachment. Int. J. Hous. Sci. Appl., 2017, 41(2), 89-100.

37. Ofoegbu, C., Chirwa, P. W., Francis, J. and Babalola, F. D., Socio-economic factors influencing household dependence on forests and its implication for forest-based climate change interventions. South. Forest., 2017, 79(2), 109-116.

38. Tynsong, H., Tiwari, B. K. and Dkhar, M., Contribution of NTFPs to cash income of the War Khasi community of southern Meghalaya, North-East India. For. Stud. China, 2012, 14(1), 47-54.

39. Padoch, C., Coffey, K., Mertz, O., Leisz, S. J., Fox, J. and Wadley, R. L., The demise of swidden in Southeast Asia? Local realities and regional ambiguities. Geogr. Tidsskr-Den., 2007, 107(1), 29-41.

40. Mishra, S., Mazumdar, S. and Suar, D., Place attachment and flood preparedness. J. Environ. Psychol., 2010, 30(2), 187-197.

41. Fernandes, W., Look (act) East policy: with or through the Northeast. In Mainstreaming the Northeast in India's Look and Act East Policy, Palgrave Macmillan, Singapore, 2018, pp. 233-251.

42. Aayog NITI, Shifting Cultivation: Towards a Transformational Approach, 2018; https://niti.gov.in/writereaddata/files/document publication/doc3.pdf

43. Tripathi, P., Tribes and forest: a critical appraisal of the tribal forest right in India. Res. J. Soc. Sci. Manage., 2016, 6(06), 1-8.

44. Singh, B. P., Biodiversity, tribal knowledge and life in India Environ. Soc. Psychol., 2017, 2(1), 1-10.

45. Chaudhry, P., Dollo, M., Bagra, K. and Yakang, B., Traditional biodiversity conservation and natural resource management system of some tribes of Arunachal Pradesh, India. Interdisc. Environ. Rev., 2011, 12(4), 338-348.

46. Sangma, R. C., Festivals and ceremonies of Garo. Garo J., 2018; https://garojournal.com/festivals-ceremonies-garos/

47. Chapin III, F. S., Mark, A. F., Mitchell, R. A. and Dickinson, K. J., Design principles for social-ecological transformation toward sustainability: lessons from New Zealand sense of place. Ecosphere, 2012, 3(5), 1-22.

48. Potschin, M. and Haines-Young, R., Landscapes, sustainability and the place-based analysis of ecosystem services. Landsc. Ecol., 2013, 28(6), 1053-1065.

ACKNOWLEDGEMENTS. This study is a part of a project funded by the Indian Council of Agricultural Research, New Delhi. We thank the respondents, tribals and key informants for their participation.

Received 2 August 2020; accepted 5 November 2020

doi: $10.18520 / \mathrm{cs} / \mathrm{v} 120 / \mathrm{i} 1 / 215-220$

\section{Assessment of colour changes in Lonar lake, Buldhana district, Maharashtra, India using remote sensing data}

\author{
Anurag Mishra, K. Abdul Hakeem*, \\ V. V. Rao, P. V. N. Rao and Santanu Chowdhury \\ National Remote Sensing Centre, Indian Space Research Organisation, \\ Hyderabad 500 037, India
}

This communication presents results of a preliminary study to understand and assess the colour changes in Lonar lake, Buldhana district, Maharashtra, India, using remote sensing data of recent years (2019 and 2020). In addition, the study has utilized IMD gridded weather data and spectral profiles of algal pigments from the published literature. In order to verify whether the colour change is a cyclic event, long-term satellite data of Landsat 8-OLI and Sentinel 2-MSI sensors from 2014 onwards were analysed using spectral response in red and green bands. It was observed that even though a cyclic pattern exists, the colour change events occurred only during the 2019 and 2020 periods. The present analysis showed a change in colour of the lake from green to brown twice during April-June 2019. However, in 2020, there was a change in colour of the lake from green to brown and eventually to pinkish-red, which was not observed earlier. Rainfall and temperature were used to identify possible causes of abiotic stress on algae population of the lake. The study observed light rainfall and reduction in temperature just prior to the colour change event during both the years. In the absence of field data, the published literature on absorption spectra of different algal pigments was reviewed to identify pigments causing brown- and red-coloured appearance of the lake. Though cause of stress on the algae population is not known and is to be precisely identified by field surveys, the change in colour of Lonar lake appears to be caused by pigment(s), like phycoerythrin and carotenoids. However, this needs to be verified in the ground through water quality analysis.

Keywords: Colour changes, lake water, pigments, remote sensing, water quality analysis.

IN the second week of June 2020, several print and electronic media reported change in colour of Lonar lake, Buldhana district, Maharashtra, India ${ }^{1,2}$ from green to pink. This was attributed primarily to the presence of algae in saline water of the lake. It was also reported that though change in colour of the lake had been observed in the past, however, the extreme tone of red colour was witnessed this year. The National Remote Sensing Centre (NRSC), Hyderabad initiated a quick preliminary study to assess the change in colour of this lake using remote

*For correspondence. (e-mail: abdulhakeem_k@nrsc.gov.in) 